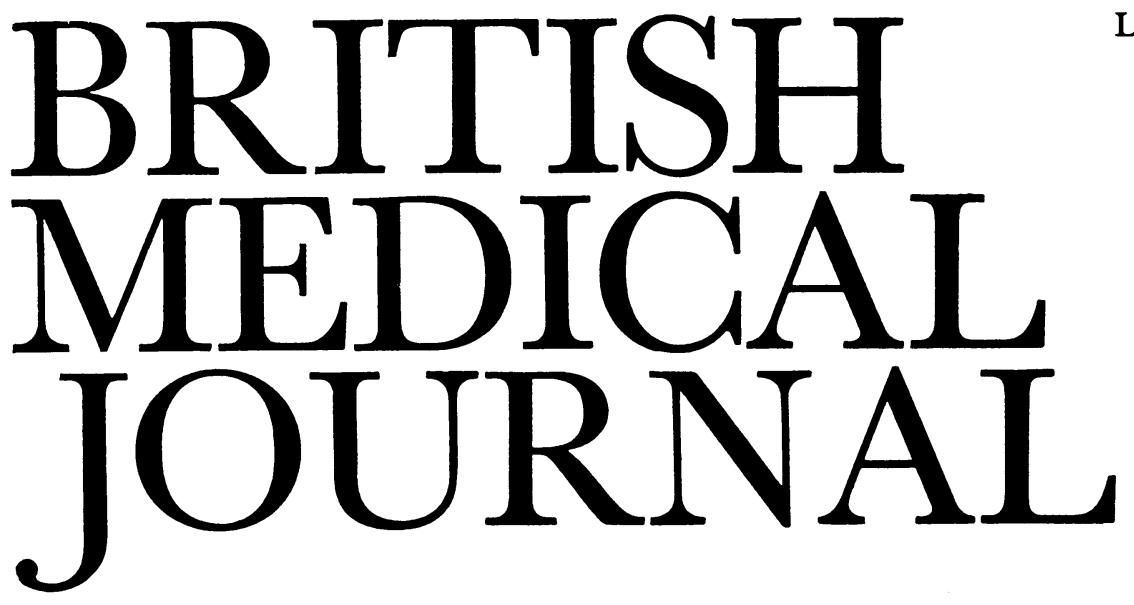

\title{
Which pill?
}

The publicity surrounding the two recent Lancet papers $^{12}$ on cancer and oral contraceptives has-as predicted ${ }^{3}$-caused public concern, and has put general practitioners in a difficult position. Women have been advised to go to their doctors for advice, but doctors have been given little time to discuss the reliability and implications of the reports-which contain a complex mixture of epidemiology and endocrinology. The patients who are asking for advice fall into three groups. Women taking the pill want to know whether to stop it or change to another brand; those who have taken the pill in the past want to know if they fall into a high risk category requiring special screening; and women who have not yet taken the pill may ask when-if ever-it will be safe to start. Before these questions can be answered the two Lancet papers must first be put into perspective.

The Oxford Family Planning Association study ${ }^{1}$ looked at the incidence of all forms of cervical neoplasia among 3154 parous women using the intrauterine contraceptive device and 6838 parous pill users (many of whom had been taking formulations with $50 \mu \mathrm{g}$ or more of oestrogen). The women on the pill had a $75 \%$ greater incidence of cervical neoplasia and the risk was related to duration of pill use. Vessey and his coauthors therefore suggested that the pill may directly affect the cervix, but confirmatory evidence for this is scanty and, as the authors point out, the effect they observed may have been due to other factors such as sexual activity. Age at first intercourse $e^{4}$ and number of partners ${ }^{5}$ are important risk factors for cervical cancer but were not documented in this studythough the finding that pill users were slightly younger at marriage and at first term pregnancy may suggest that they began intercourse earlier than women using intrauterine contraceptive devices. This trend may have been strong enough to override the opposing trend in other risk factors. Other similar studies have produced conflicting results. ${ }^{1}$ Further investigation is needed to confirm or refute Vessey's suggestion that the pill may have a direct effect on the cervix in addition to its indirect effect via sexual activity. Recent publicity may have given women an exaggerated impression of the risks: in Vessey's study the background risk of all types of cervical neoplasia (including dysplasia) was 1 in 1000 woman years and this was doubled by prolonged use of the pill. Preliminary data from the Royal College of General Practitioners' study suggest that the excess risk of invasive cervical carcinoma among pill users is less than 1 in 14000.6 All cancers in Vessey's study were detected at a curable stage, and regular cytological screening is, of course, essential for pill users of any age.

The second paper was an American study of breast cancer. ${ }^{2}$ Using telephone interviews the researchers compared the contraceptive histories of 314 Californian women with breast cancer diagnosed before the age of 37 with those of 314 neighbourhood controls. Pike and his coauthors found that the women with cancer had used the pill for an average of 49.6 months, compared with 39.2 months among controls, and that they were more likely to have used the pill for long intervals before the age of 25 . The study did not attempt to verify the histories given by the women (who were in many cases being asked to recall events more than 12 years previously) or to eliminate possible observer bias. Pike's results are unique, for a review of 12 recent large case control studies and five cohort studies of pill users shows no overall association between use of the pill and breast cancer, ${ }^{7}$ though in two studies $^{89}$ there were trends of increased risk in young pill users, which were of no statistical significance ${ }^{8}$ or of borderline significance. ${ }^{9}$ In a preliminary report on their present study Pike's group had implicated early miscarriage or pill use before first pregnancy as risk factors, ${ }^{10}$ but when this work was repeated in England using personal interviews of 1176 women with cancer and 1176 controls Vessey failed to confirm Pike's results $^{11}$; if anything, he found a protective effect of pill use. Vessey suggested that this disparity might be due to methodological factors including the selection of cases for interview: in both their preliminary report ${ }^{10}$ and their present paper ${ }^{2}$ Pike's group interviewed only two thirds of the eligible cases. Nevertheless, the numbers of young pill users in all these studies are small, ${ }^{12}$ and one cannot ignore the point that Californian girls may have led the world in prolonged pill use early in life and so may be the first to show its effects. ${ }^{3} \mathrm{~A}$ meeting is due to take place soon between groups of epidemiologists with data about young pill users, and though it is to be hoped that some consensus will emerge it seems likely that further investigation will be needed.

The most controversial part of the Californian study ${ }^{2}$ was its investigation into the role of different brands of the pill. It is surprising that each of the $\mathbf{4 7 0}$ former pill users in the study felt able to identify over the telephone the brand she had used many years previously. Although the accuracy of such recall is at most $75 \%{ }^{12 a}$ and no verification of these data was attempted Pike and his coauthors named certain brands as being associated with a risk of cancer. All but one were 
formulations with a high oestrogen content, but Pike concentrated on their "progestogen potency" and reproduced from a textbook ${ }^{13}$ a table of progestogen potencies calculated from the Swyer-Greenblatt test ${ }^{14}$-a "delay in menses" test originally described by Swyer in $1962 .{ }^{15}$ This test entails giving $100 \mu \mathrm{g}$ of oestrogen along with the progestogen, and Swyer has warned $^{1617}$ that its results cannot be applied to modern formulations of the pill containing $50 \mu \mathrm{g}$ or $30 \mu \mathrm{g}$ of oestrogen. It is now known that oestrogen modifies the action of progestogens-for example, by introducing synthesis of progesterone receptors ${ }^{18}$ - and Swyer has published a new list of the potencies of progestogens combined with $50 \mu \mathrm{g}$ of oestrogen. ${ }^{16}$ This list is quite different from the one published by $\mathrm{Pike}^{2}$ and that circulated recently by the Committee on Safety of Medicines, ${ }^{19}$ which for some reason ignored Swyer's recent work. The tables of "progestogen potency" produced by Pike and by the Committee on Safety of Medicines are incorrect and are certainly irrelevant to formulations of the pill in current use. The inaccuracy of his table calls into question Pike's whole theory of "progestogen potency" as a risk factor for breast cancer.

Pike's paper also includes a hypothesis of the cause of breast cancer. ${ }^{2}$ Ovarian steroids are known to be implicated ${ }^{20}$ in the aetiology of breast cancer, and oestrogen (which may be carcinogenic to the endometrium) is usually assumed ${ }^{21-23}$ to be the hormone concerned. Progesterone (which protecst against endometrial carcinogenesis) is thought ${ }^{24}$ to protect against breast cancer, and indeed low circulating progesterone concentrations ${ }^{25}$ and anovulatory cycles ${ }^{26}$ have been implicated as risk factors for breast cancer. Pike, ${ }^{2}$ however, suggests that because mitotic activity in the breast ${ }^{27-30}$ (unlike the uterus) is greatest towards the end of the menstrual cycle breast epithelium must be fundamentally different from endometrium -a theory which is difficult to reconcile with his suggestion that carcinogenicity can be measured by the "delay in menses" test. Although his hypothesis is occasionally inconsistent and explains few of the observed facts about breast cancer, it is a useful advance on previous theories which attempted to identify a single hormone responsible for breast cancer. It is very likely (as Pike suggests at one point) that the answer to the ovary's effect on breast carcinogenesis lies with the interaction of oestrogen and progesterone rather than with oestrogen alone. Nevertheless, Pike's "progesterone" theory as it stands is still as unsatisfactory as the previous "oestrogen" theories his group questioned. ${ }^{31}$

How then are our three groups of patients to be counselled? Provided they are taking a low oestrogen formulation women already on the pill should not change brands in a pointless search for "low progestogen potency." Women continuing on the pill may worry that they are increasing their risk of cervical neoplasia but this suggestion remains unproved and the effect (if it exists) would be balanced by the pill's apparent protective effect ${ }^{2}$ against endometrial and ovarian cancers-which are not easily detectable by screening. Women over the age of 25 starting or continuing the pill have no cause to worry about the risk of breast cancer. What about those under 25 ? The suggestion of a risk of breast cancer remains unproved and indeed disputed and is restricted to women who have used high oestrogen formulations for more than two years. There is no reason to advise a young girl to stop a low oestrogen pill after two or more years' use. Girls worried by the uncertainty caused by Pike's paper ought to continue on the pill until the epidemiologists have had a chance to meet again, and if the uncertainty still continues they will then have to decide whether they prefer the pill with its faint question marks or a less satisfactory method of contraception.

Finally, what advice should be given to older women $c$ worried because they took the pill for several years before they $\widehat{\widehat{\rho}}$ were 25? Although they can be reassured by the many negative studies they are likely to want advice about screening for breast cancer. The American Cancer Society's guidelines ${ }^{32}$ 罗 for women aged between 20 and 40 recommend monthly self examination with a clinical examination every three $\overrightarrow{\vec{F}}$ years-which in the United Kingdom could be done by $\frac{\infty}{\sigma}$ general practitioners, Family Planning Association clinics, or well woman clinics. More frequent clinical examination is $\overline{\bar{\omega}}$ probably unnecessary, ${ }^{33}$ and mammography should be $\bar{\varnothing}$ performed only if indicated by the findings on clinical examination. Mammography is never indicated as a routine screening procedure in asymptomatic women under the age of 35 .

\section{JAMES DRIFE}

Senior Lecturer and Consultant in Obstetrics and Gynaecology, Leicester Royal Infirmary,

Leicester LE2 7LX

${ }^{1}$ Vessey MP, Lawless M, McPherson K, Yeates D. Neoplasia of the cervix uteri and contraception: a possible adverse effect of the pill. 0 Lancet 1983;ii:930-4.

2 Pike MC, Henderson BE, Krailo MD, Duke A, Roy S. Breast cancer in $\vec{N}$ young women and use of oral contraceptives: possible modifying $\mathrm{N}$ effect of formulation and age at use. Lancet 1983;ii:926-30.

${ }^{3}$ Anonymous. Oral contraceptives and neoplasia [Editorial]. Lancet 1983; ii:947-8.

${ }^{4}$ Rotkin ID, Cameron JR. Clusters of variables influencing risk of cervical cancer. Cancer $1968 ; 21: 663-71$.

${ }^{5}$ Harris RWC, Brinton LA, Cowdell RH, et al. Characteristics of women with dysplasia or carcinoma in situ of the cervix uteri. $\mathrm{Br} \mathcal{F}$ Cancer $\mathscr{\wp}$ $1980 ; 42: 359-69$.

${ }^{6}$ Kay CR. Oral contraceptives and cancer. Lancet 1983 ;ii:1018.
${ }^{7}$ Kalache A, McPherson K, Barltrop K, Vessey MP. Oral contraceptives and breast cancer. Br f Hosp Med 1983;30:278-83.

8 Trapido EJ. A prospective cohort study of oral contraceptives and breast cancer. $\mathcal{F}$ Natl Cancer Inst 1981;67:1011-5.

${ }^{9}$ Royal College of General Practitioners. Breast cancer and oral contra- $\frac{\mathrm{Q}}{\mathbb{D}}$ ceptives: findings in the Royal College of General Practitioners Study. @ Br Med ₹ $1981 ; 282: 2089-93$.

10 Pike MC, Henderson BE, Casagrande JT, Rosario I, Gray GE. Oral contraceptive use and early abortion as risk factors for breast cancer in young women. Br $\mathcal{F}$ Cancer $1981 ; 43: 72-6$.

11 Vessey MP, McPherson K, Yeates D, Doll R. Oral contraceptive use and abortion before first term pregnancy in relation to breast cancer risk. Br f Cancer 1982;45:327-31.

12 Vessey MP. Oral contraceptives and breast cancer. In: Wald NJ, ed. Proceedings of the symposium on negative results in cancer epidemiology. Lyons: International Agency for Research in Cancer, 1984 (in press).

12a Glass R, Johnson B, Vessey M. Accuracy of recall of histories of oral contraceptive use. Br F Prev Soc Med 1974;28:273-5.

${ }^{13}$ Misnell DR. Oral steroids. In: Misnell DR, Davajan V, eds. Reproductive endocrinology, infertility, and contraception. Philadelphia: Davis, 1979. $\mathrm{O}$

${ }^{14}$ Greenblatt RB. Progestational agents in clinical practice. Med Sci 1967; 18:37-49.

15 Swyer GIM, Little V. Action and uses of orally active progestational steroids. Proc $R$ Soc Med 1962;55:861.

16 Swyer GIM. Potency of progestogens in oral contraceptives-further delay of menses data. Contraception 1982;26:23-7.

17 Swyer GIM. Oral contraceptives and cancer. Lancet 1983;ii:1019.

18 Janne O, Kontula K, Luukkainen T, Vihko R. Oestrogen induced pro- $\omega$ gesterone receptor in human uterus $f$ Steroid Biochem 1975;6.501-9.

${ }^{9}$ Committee on Safety of Medicines. Use of combined oral contraceptive pills and cancer. Letter to doctors in Britain, 20 October 1983.

${ }^{20}$ McMahon B, Cole P, Brown J. Etiology of breast cancer: a review. f Natl Cancer Inst 1973;50:21-42.

${ }^{21}$ Korenman SG. Oestrogen window hypothesis of the aetiology of breast cancer. Lancet 1980; i:700-1.

${ }^{22}$ Drife JO. Breast cancer, pregnancy, and the pill. Br Med $\mathcal{F} 1981 ; 283$ : 778-9.

${ }^{23}$ Nandi S. Role of hormones in mammary neoplasia. Cancer Res 1978; 38:4046-50.

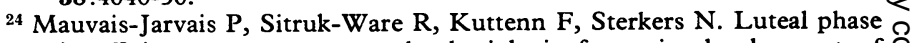
insufficiency: a common pathophysiologic factor in development of benign and malignant breast diseases. Commentaries on Research in Breast Disease 1979;1:25-9. 
${ }^{25}$ Bulbrook RD, Moore JW, Clark CMG, Wang DY, Tong D, Hayward JL. Plasma oestradiol and progesterone levels in women with varying degrees of risk of breast cancer. Eur $\mathcal{F}$ Cancer 1978;14:1369-75.

26 Sherman BM, Korenman SG. Inadequate corpus luteum function: a pathophysiological interpretation of human breast cancer epidemiology. Cancer $1974 ; 33: 1306-12$.

27 Masters JRW, Drife JO, Scarisbrick JJ. Cyclic variation of DNA synthesis in human breast epithelium. $\mathcal{F}$ Natl Canc Inst 1977;58:1263-5.

28 Drife JO. The effects of parity and the menstrual cycle on the normal mammary gland and their possible relationship to malignant change. MD Thesis, University of Edinburgh, 1981

${ }^{29}$ Ferguson DJP, Anderson TJ. Morphological evaluation of cell turnover in relation to the menstrual cycle in the "resting" human breast. $\mathrm{Br} F$ Cancer $1981 ; 44: 177-81$.

${ }^{30}$ Anderson TJ, Ferguson DJP, Raab GM. Cell turnover in the "resting" human breast: influence of parity, contraceptive pill, age and laterality. Br F Cancer 1982;46:376-82.

${ }^{31}$ Henderson BE, Pike MC, Casagrande JT. Breast cancer and the oestrogen window hypothesis. Lancet 1981 ;ii:363-4.

32 American Cancer Society. Mammography 1982: a statement of the American Cancer Society. CA 1982;32:226-30.

${ }^{33}$ Hamilton T, Loudon NBL, Prescott RJ, Rankin ME. Detection of breast disease in a Family Planning Association clinic. Scott Med $\mathcal{f}$ $1976 ; 21: 31-6$.

\section{Biochemists nearer the patient?}

Many hospital clinicians, especially in specialties relating to intensive care, will have come under pressure from instrument and reagent manufacturers to sell them new systems to provide rapid bedside chemical analyses without reference to the laboratory. Such instruments are widely used already for measuring blood gases and blood glucose concentrations. Clinicians tend to take such instruments at their face value and are often uncritical about the quality of results. On the other hand, laboratory workers in clinical biochemistry often see the new technology as a threat. Professor Vincent Marks (whose provocative leading article on "Clinical biochemistry nearer the patient" focused attention on the issue earlier this year ${ }^{1}$ ) and Professor George Alberti organised a conference on these developments at the University of Surrey in September.

The message from industrial speakers was clear: "We have the technology." Most commonly requested biochemical tests can be done at the bedside here and now-no mess, no fuss, no delay-and the manufacturers believe that they can see a new and untouched market. The experts traced the development of side room testing from humble litmus paper to solid phase immunoassays for theophylline on a dipstick. James Weaver from Harvard described recent developments ranging from continuous electrolyte measurements in a cannula to gas chromatography in a shirt button. The miniaturisation of these instruments excited anyone with even a remote interest in chemistry-but the prospect of non-laboratory workers getting hold of such a shirt sent shivers through the audience.

As Tom Craig, a health economist with Du Pont, elegantly explained, however, bedside tests are expensive in both time and reagents. Testing a single sample on the ward will be about seven times as expensive as doing a batch of 10 in the laboratory, and meter testing of blood glucose concentrations costs at least four times as much as does a fast laboratory based method. So is it worth the expense?

The clinicians who spoke were rather unenthusiastic about ward based tests, except where speed was clinically essential. Julian Leigh, director of the Royal Surrey County Hospital intensive care unit, argued that the ideal solution is siting the main hospital emergency laboratory within the intensive care unit, staffed from the central laboratory. Professor Harry Lee emphasised that accuracy and precision were much more important than speed in managing patients in renal failure. The final, easily forgotten truth was brought out by Professor Harold Ellis: laboratory tests play a small part in the clinical assessment of patients. The last thing the houseman should want or need to do at the bedside of a patient with an "acute abdomen" is to struggle himself with biochemical tests.

What of the analytical quality of these test results? Professor George Alberti showed that diabetics, who have a strong vested interest in getting the result right, are good at monitoring their own blood glucose concentrations at home. When tests are performed by doctors, nurses, or medical students the results overall are of poor quality. Professor Tom Whitehead showed that such results contain a blunder rate of at least $10 \%$ -many of them real howlers. Almost everyone at the conference had his own favourite anecdotal horror story of how the consultant/houseman/sister/cleaner had put the strip upside down in the meter or put Sellotape on the bilirubinometer cuvette.

Furthermore, said Nicholas Davidson, a member of the London bar, the courts have high expectations of what constitutes "reasonable skill and care." When harm comes to a patient as the result of error in test results the courts may seek a reason, if skilled laboratory personnel were available, why the test needed to be performed by someone else. Records to show that reasonable care was taken assume even greater importance than usual if the test is performed by an unskilled person. The lack of supervision of tests performed outside laboratory areas should concern the legal advisors of our health authorities, quite apart from clinical concern about their quality.

Quality does not, however, begin and end with the analytical procedure. The strongest theme running through the conference was that clinical biochemists must get back into the wards and clinics. As Fred Mitchell, of Northwick Park, said on another occasion, all too often clinical biochemists are people who "provide pieces of paper in response to the receipt of pieces of paper from people whom they rarely see in parts of the hospital into which they never go." A splendid opportunity is now provided by modern technology for biochemists to emerge from the basement to function as members of the team looking after patients. The considerable benefits of this approach were described by Oren Zinder from Israel, where clinicians recognise the value of the clinical biochemist's advice on test reliability in diagnosis, as well as their personal concern in guiding special specimens through the central laboratory. Many clinical biochemists will feel unhappy about this metamorphosis, some for lack of interest, some for a perceived lack of time, and others because of lack of encouragement and a frosty reception on the wards. Such attitudes can change only with effort and good will, and unfortunately clinical biochemists in general have a lot of ground to make up which they lost in their massive withdrawal into big automated and computerised laboratories in the 1970s.

Critical care areas are the most obvious places for clinical biochemistry staff to get back to the bedside. Another area which would benefit is therapeutic drug monitoring, where the clinical biochemist can help in providing rapid measurements of drug concentrations in the outpatient clinic-and the results can be interpreted during the consultation in the light of the many complex factors influencing pharmacokinetics. We should contrast this approach with centralised testing, in which the laboratory receives specimens accompanied by the bare minimum of identifying information and produces and 